\title{
CARACTERÍSTICAS E DIFICULDADES DE PRODUÇÃO DOS AGRICULTORES FAMILIARES INSERIDOS EM FORMAS DIFERENCIADAS DE COMERCIALIZAÇÃO, NA MICRORREGIÃO DE ANDRADINA-SP
}

Flaviana Cavalcanti da Silva ${ }^{1}$, Antonio Lázaro Sant'Ana ${ }^{2}$, Ana Heloisa Maia ${ }^{3}$, Paula Suemy Landi Koga ${ }^{4}$, Valéria da Silva Modenese ${ }^{5}$

\footnotetext{
${ }^{1}$ Doutoranda em Agronomia na Faculdade de Engenharia - UNESP Campus de Ilha Solteira (SP).

${ }^{2}$ Engenheiro Agrônomo, Professor Adjunto (Livre Docente) da Faculdade de Engenharia - UNESP Campus de Ilha Solteira (SP).

${ }^{3}$ Engenheira Agrônoma, Professora da Universidade do Estado do Mato Grosso e Doutoranda em Agronomia na Faculdade de Engenharia - UNESP Campus de Ilha Solteira (SP).

${ }^{4}$ Engenheira Agrônoma, Doutoranda em Agronomia na Faculdade de Engenharia - UNESP Campus de Ilha Solteira (SP).

${ }^{5}$ Engenheira Agrônoma, Mestranda em Agronomia na Faculdade de Engenharia - UNESP Campus de Ilha Solteira (SP).
}

RESUMO: Este trabalho analisa os sistemas de cultivo de produtores familiares da Microrregião de Andradina/SP, a fim de identificar os fatores técnico-produtivos que contribuem para a sazonalidade da produção vegetal ou que limitam a produção e/ou o leque de culturas cultivadas; os quais dificultam, também, o processo de comercialização. Os dados foram levantados por meio da realização de entrevistas, com a aplicação de questionários junto a 40 produtores familiares de quatro municípios da Microrregião (Ilha Solteira, Castilho, Andradina e Pereira Barreto). Os resultados revelaram que, aliadas às deficitárias condições de infraestrutura dos lotes/propriedades, as limitações referentes à assistência técnica e extensão rural consistem em consideráveis entraves para o desenvolvimento dos sistemas de cultivo, com reflexos negativos no potencial das famílias em gerar renda nas áreas exploradas. A adoção de determinadas práticas agronômicas de nível tecnológico e custos relativamente baixos poderia contribuir para o aumento da eficiência produtiva. Tais aspectos indicam a necessidade de políticas públicas que facilitem investimentos específicos na infraestrutura de produção, bem como, o estabelecimento de estratégias de assistência técnica e extensão rural que favoreçam a construção de conhecimentos focados nas debilidades e potencialidades locais, para a superação das dificuldades identificadas.

Palavras-chave: Infraestrutura produtiva. Assistência técnica. Agricultura familiar.

FEATURES AND DIFFICULTIES OF PRODUCTION OF THE FAMILY FARMERS, INSERTED IN DIFFERENTIATED COMMERCIALIZATION FORMS, IN ANDRADINA REGION, SÃO PAULO STATE, BRAZIL

\begin{abstract}
This work aims to investigate the farming systems of family farmers at the region of the Andradina-SP, aiming to identify the techno-productive factors that contribute
\end{abstract}

Cultura Agronômica, Ilha Solteira, v.24, n.1, p.103-118, 2015 
to the Seasonal farming or limit the production and/or the range of grown cultures, so also hinder the process of commercialization. The data was gotten through interviews and questionnaires applied to 40 family farmers, divided into four cities at the micro-region (Ilha Solteira, Castilho, Andradina e Pereira Barreto). The results of the research showed that added to the precariousness of the studied properties infrastructure, the deficiency related technical assistance and rural extension are the main aspects responsible for growing system deficiencies, whose negative effects reflect on the trading process and limit the families' potential in generating income from their properties. The adoption of certain agronomic practices, low technological level and relatively low costs could contribute to increase production efficiency. These aspects indicate the need for public policies that facilitate specific investments in production infrastructure, as well as the establishment of strategies for technical assistance and rural extension that favor the construction of knowledge focused on local potentials and weaknesses, to overcome the difficulties identified.

Key words: Productive infrastructure. Technical assistance. Family farmers.

\section{INTRODUÇÃO}

Segundo Costabeber e Caporal (2003), a agricultura familiar representa a forma de organização mais adequada para dinamizar o desenvolvimento agrícola e rural, contudo, o setor se apresenta como um segmento que tem sérias dificuldades para sua reprodução social. Para Favero et al. (2007), o papel dos eventos críticos na determinação da condição sócio-econômica das famílias rurais está ligado a um conjunto de fenômenos; cujos efeitos implicam em riscos para a reprodução social destas famílias, englobando desde mudanças na conjuntura econômica a catástrofes naturais. Apesar disso, a capacidade de superar limitações é vista por Buainain et al. (2003) como uma característica que potencializa a relevância da agricultura familiar, na medida que os sistemas de produção adotados por estes produtores se mostram viáveis, embora o contexto ambiental não seja favorável, os recursos sejam escassos e as políticas institucionais, direcionadas ao setor, limitadas.

$\mathrm{Na}$ fase inicial da pesquisa que originou o presente trabalho, buscou-se investigar as estratégias diferenciadas de comercialização, baseadas em vendas diretas. Ao serem questionados sobre eventuais problemas presentes nos modelos de comercialização utilizados, muitos dos agricultores entrevistados afirmaram que não encontravam dificuldades para comercializar a produção, mas sim para conseguir produzir a quantidade demandada pelo mercado durante o ano todo. Tal aspecto, aliado a outros inicialmente observados, fundamentaram o presente trabalho, que objetiva investigar os sistemas de cultivo dos produtores, visando identificar os fatores técnico-produtivos que contribuem para a sazonalidade da produção vegetal ou que limitam a produção e/ou o leque de culturas cultivadas, de modo a refletir negativamente no processo de comercialização. Os resultados apresentados poderão contribuir para a orientação de políticas públicas que visem superar os entraves presentes nos sistemas de cultivo que podem limitar a capacidade das famílias no que se refere à geração de renda, nos estabelecimentos.

Cultura Agronômica, Ilha Solteira, v.24, n.1, p.103-118, 2015 


\section{MATERIAL E MÉTODOS}

Após a análise dos resultados obtidos na fase inicial da pesquisa destinada à investigação das estratégias diferenciadas de comercialização utilizadas pelos agricultores familiares da Microrregião de Andradina/SP (2008), foi elaborado um questionário complementar, destinado ao levantamento detalhado dos sistemas de cultivo dos produtores familiares tradicionais, assentados e reassentados pertencentes à referida Microrregião. Inicialmente, foi realizada a seleção de $80 \%$ dos 50 produtores familiares pesquisados na fase inicial, com base nos dados referentes à produção. Foram excluídos 10 lotes/propriedades em virtude dos agricultores realizarem somente vendas eventuais de produtos normalmente utilizados para o autoconsumo (não fazem plantios específicos destinados à comercialização) e/ou comercializarem apenas produtos específicos da produção animal.

Os questionários foram então aplicados junto a 40 produtores familiares distribuídos entre os quatro municípios pesquisados na primeira fase: dez produtores do Assentamento Estrela da Ilha (Ilha Solteira); nove agricultores do Projeto Cinturão Verde (Ilha Solteira/SP); seis produtores pertencentes ao Assentamento Terra é Vida (Pereira Barreto/SP); quatro agricultores pertencentes ao Assentamento São Joaquim (Castilho/SP); quatro produtores do Assentamento Timboré (Andradina/SP); três produtores do Assentamento Rio Paraná (Castilho/SP); três agricultores do Reassentamento Nossa Senhora de Fátima (Pereira Barreto/SP), além de um agricultor familiar tradicional do município de Ilha Solteira.

Os dados foram coletados junto aos produtores em visitas realizadas aos lotes/propriedades durante o segundo semestre de 2009. Buscou-se conduzir as entrevistas sem interromper as atividades que estavam sendo desempenhadas, a fim de possibilitar a observação dos trabalhos desenvolvidos, bem como, estabelecer uma abordagem que propiciasse uma maior liberdade ao produtor para expor as peculiaridades dos sistemas de cultivo empregados.

\section{A Microrregião Geográfica de Andradina/SP}

A Microrregião Geográfica de Andradina pertence à mesorregião de Araçatuba e está localizada no noroeste do estado de São Paulo, sua área abrange $6.888,149 \mathrm{~km}^{2}$, distribuída entre onze municípios. Segundo levantamento do IBGE - Instituto Brasileiro de Geografia e Estatísticas (2006), sua população foi estimada em 179.591 habitantes e densidade demográfica em 26,1 hab./km².

A Microrregião de Andradina/SP é caracterizada pela forte presença de propriedades agrícolas familiares, com destaque para os assentamentos rurais que em 2009 somavam 36 projetos com mais de 3.200 famílias assentadas (INCRA, 2010), além dos projetos de reassentamento da CESP (Companhia Energética de São Paulo). A principal atividade agrícola refere-se à pecuária, com destaque para a pecuária leiteira, no caso da agricultura familiar. Embora as áreas destinadas à pastagem ocupem grande parte da área total da unidade produtiva familiar e estejam presentes em cerca de $90 \%$ das Unidades de Produção Agrícola - UPA's (CATI, 2007/08), estas mantêm outras criações e áreas destinadas à 
produção vegetal, de modo a conservar a diversidade típica dessa forma de exploração agropecuária, tanto no caso da agricultura familiar tradicional, como, também, dos assentamentos rurais.

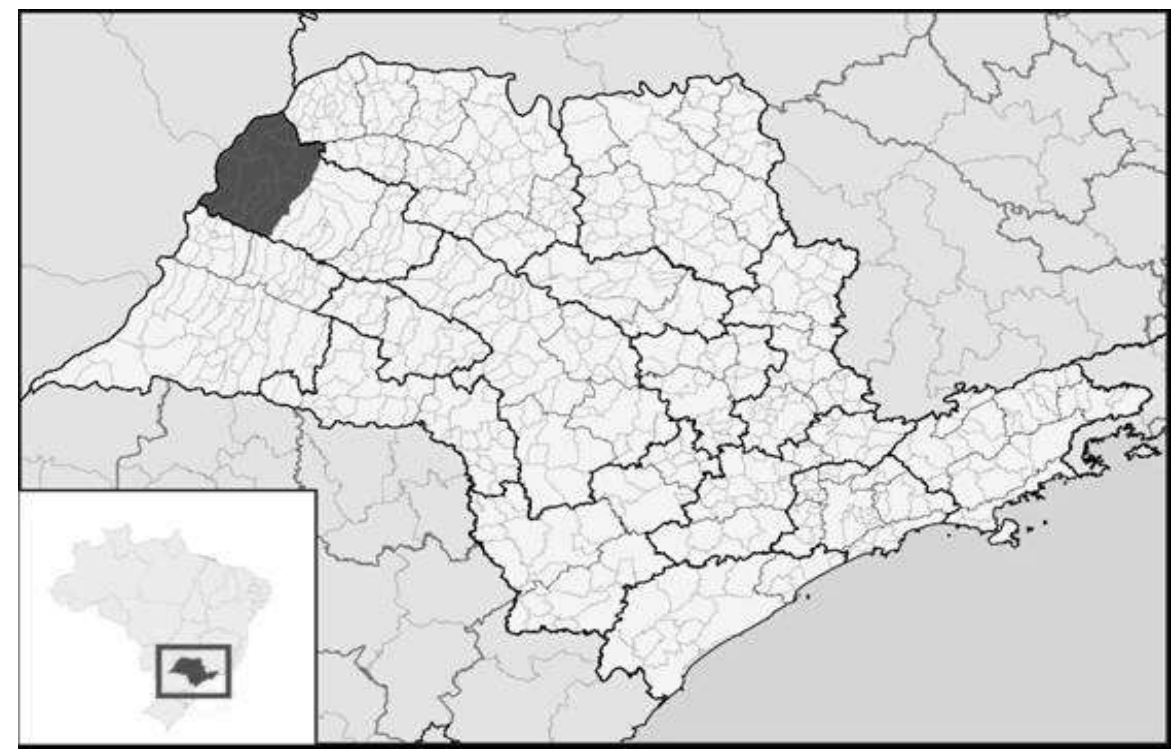

Figura 1. Microrregião de Andradina (área em destaque).

Fonte: http://www.cidadespaulistas.com.br

O Levantamento Censitário de Unidades de Produção Agropecuária (LUPA) realizado em 2007/08, sob coordenação da CATI (Coordenadoria de Assistência Técnica Integral), órgão vinculado à Secretaria de Agricultura e Abastecimento do Governo do Estado de São Paulo, aponta um total de 7.502 UPA's ${ }^{1}$, na Microrregião de Andradina, distribuídas entre $712.738,8$ hectares. Ao se verificar o percentual de UPA's segundo a faixa de área, nota-se que 57,46\% das unidades apresentam áreas inferiores a 20 hectares, o que evidencia a importância da agricultura familiar na Microrregião, embora estas representem menos de $7 \%$ da área total (Tabela 1). O percentual elevado de UPA's com até 20 hectares se deve, sobretudo, à significativa quantidade de lotes de projetos de reforma agrária (assentamentos), bem como de reassentamentos, presentes na região.

Tabela 1. Estrutura Fundiária da Microrregião de Andradina - São Paulo - 2007/08.

\begin{tabular}{l|c|c|c|c}
\hline FAIXA DE ÁREA & NÚMERO DE UPA'S & UPAS (\%) & ÁREA (ha) & ÁREA (\%) \\
\hline Até 20 ha & 4311 & 57,46 & $46.793,2$ & 6,57 \\
\hline $20,1-50$ ha & 1468 & 19,57 & $46.974,9$ & 6,59 \\
\hline $50,1-100$ ha & 612 & 8,16 & $44.249,9$ & 6,21 \\
\hline $100,1-200$ ha & 440 & 5,86 & $61.550,5$ & 8,64 \\
\hline $200,1-500$ ha & 368 & 4,90 & $115.927,3$ & 16,27 \\
\hline $500,1-1000$ ha & 173 & 2,31 & $123.020,1$ & 17,26 \\
\hline$>1000$ ha & 131 & 1,75 & $274.222,9$ & 38,47 \\
\hline
\end{tabular}

Fonte: CATI (2009).

Faixas entre 200,1 e 500 hectares ocupam 16,27\% do total de área ocupada com

\footnotetext{
${ }^{1}$ Enquanto a definição de UPA aproxima-se do conceito de imóvel rural (utilizado pelo INCRA), a definição de estabelecimento do IBGE inclui também como unidades diferentes aqueles trabalhados por arrendatários e parceiros.
}

Cultura Agronômica, Ilha Solteira, v.24, n.1, p.103-118, 2015 
UPA's e representam 4,90\% do total de Unidades. Com relação às unidades com faixas de terra superior a 1000 ha, nota-se que estas correspondem a menos de $2 \%$ do número total de UPA'S presentes na Microrregião, no entanto, ocupam 38,47\% da área total. Reflexo da concentração fundiária, nota-se na Microrregião uma estrutura com um grande número de propriedades ocupando uma pequena área e um pequeno número de grandes propriedades que ocupa uma vasta área; situação, ainda, bastante recorrente no espaço agrário brasileiro.

\section{RESULTADOS E DISCUSSÃO}

Ao levantar informações destinadas à caracterização dos produtores e famílias, constatou-se que a maioria dos titulares dos lotes/propriedades pesquisados possui idade superior a 55 anos e, no que se refere à escolaridade, cerca de $70 \%$ dos produtores não ultrapassaram o ensino fundamental e $13 \%$ não frequentaram unidades de ensino.

Em relação à mão de obra, as atividades nos lotes/propriedades são majoritariamente desempenhadas por familiares, sendo que em $60 \%$ dos casos a mão de obra é exclusivamente familiar, com predominância do trabalho do casal. A maioria das famílias também complementa o orçamento com algum tipo de renda não-agrícola, particularmente, a aposentadoria.

Entre os entrevistados, 55\% dos produtores trabalham nos respectivos lotes/propriedades há no máximo seis anos. Exceto um produtor, os demais inclusos nesse percentual pertencem ao Assentamento Estrela da Ilha (10), ao Assentamento Terra e Vida (6) e ao Assentamento São Joaquim (4), criados nos anos de 2005, 2004 e 2003, respectivamente. O Assentamento Rio Paraná (3) e o Assentamento Timboré (4), cujas áreas começaram a ser ocupadas no ano de 1991, concentram agricultores que trabalham nos atuais lotes há mais de 16 anos. Já os nove agricultores pertencentes ao Projeto Cinturão Verde (criado em 1984) trabalham nas respectivas áreas há um tempo que varia de 9 a 24 anos. Em relação ao tempo de trabalho na agricultura, observou-se que a grande maioria dos entrevistados desempenha atividades agrícolas há mais de 20 anos.

A área média dos lotes/propriedades aqui analisados é de 11,15 ha. Muito embora, as áreas destinadas à pastagem ocupem aproximadamente $70 \%$ da área média dos estabelecimentos, ao se analisar o número de culturas por lote/propriedade, constatou-se uma considerável diversidade na produção, tipicamente vista no cenário da agricultura familiar. A bovinocultura está presente em 30 propriedades/lotes (75\%), com um número médio de 16 cabeças por estabelecimento e está voltada, sobretudo, para a produção leiteira. A produção de leite consiste na principal atividade geradora de renda para a agricultura familiar da região (em alguns casos é a única), mas observou-se no decorrer da pesquisa uma considerável sazonalidade na produção entre os produtores pesquisados: a média observada durante o período das águas foi de 56 litros/dia, já no período seco a média foi de 27 litros/dia (uma drástica redução de 52\%). Tal sazonalidade está estreitamente relacionada com o longo período de estiagem da região, que pode se prolongar de maio ou junho até outubro, e à deficiente suplementação da alimentação do rebanho realizada pelos produtores neste período.

Cultura Agronômica, Ilha Solteira, v.24, n.1, p.103-118, 2015 


\section{Caracterização dos sistemas de cultivo - Principais culturas}

Em média, em cada estabelecimento agropecuário pesquisado são exploradas sete culturas distintas, sendo que destas, quatro são destinadas à comercialização. Souza et al. (2008) afirmam que uma das características da produção familiar refere-se à policultura, sendo que a especialização em um único produto implicaria em riscos para os agricultores familiares, ao se considerar a possibilidade de situações de quebra de safra ou de redução drástica nos preços dos produtos. Ainda segundo o autor, a policultura permite, comparativamente à especialização, o uso regular da mão de obra familiar ao longo do ano, de modo a evitar o subemprego estacional.

Ao caracterizar a exploração vegetal dentre agricultores pesquisados, constatou-se que predominam as culturas anuais e as olerícolas que não apresentam elevadas exigências em relação a insumos modernos e outras tecnologias mais sofisticadas, que demandariam investimentos específicos para implantação. Assim, a opção por tais culturas está relacionada à necessidade da exploração de espécies adaptadas às condições climáticas e com características de cultivo condizentes com a infraestrutura disponível (sem irrigação). Por meio da Figura 2, observa-se que a mandioca é a mais cultivada, presente em $73 \%$ dos lotes/propriedades, sendo que a maioria (60\%) dos agricultores destina a produção desta cultura exclusivamente para o autoconsumo.

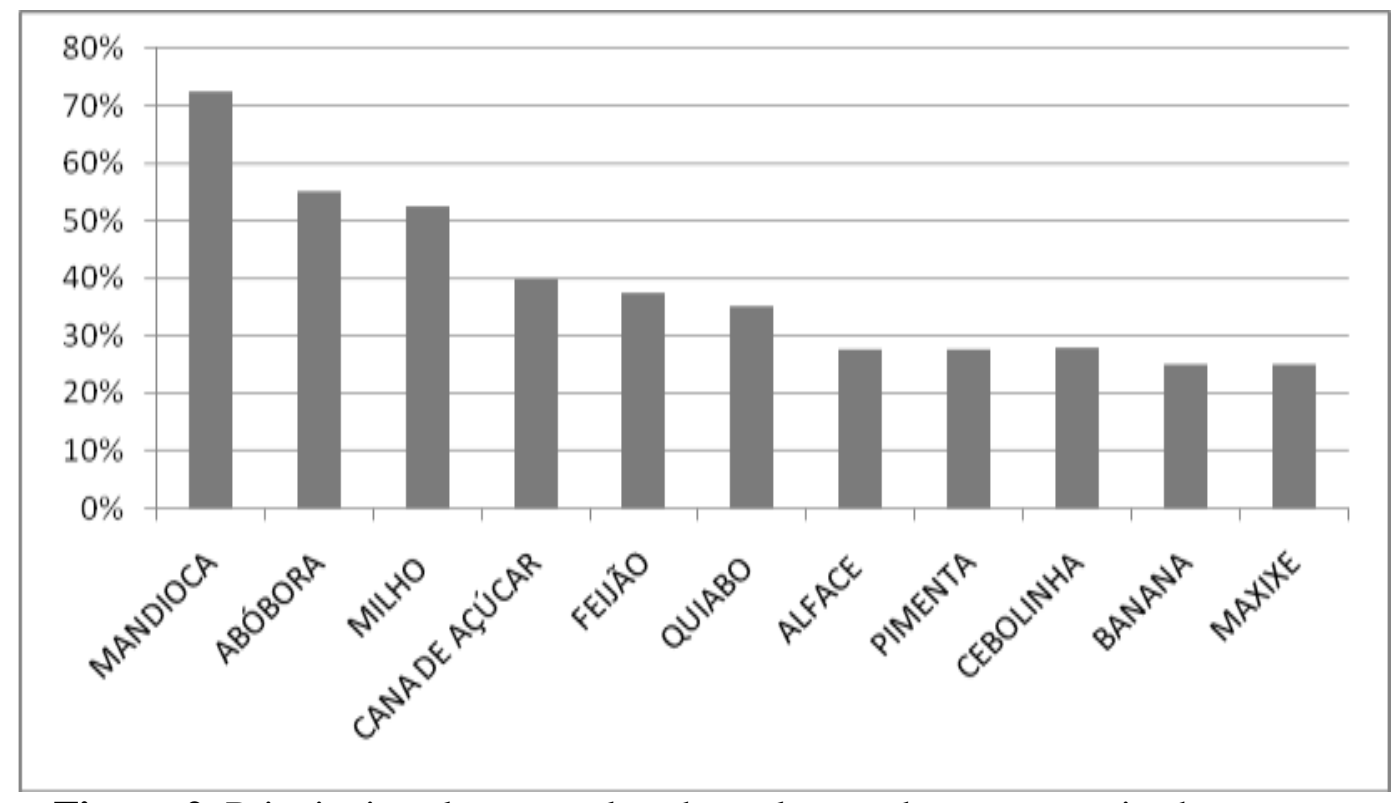

Figura 2. Principais culturas exploradas pelos produtores pesquisados.

Fonte: Dados da pesquisa, 2009.

O milho está presente em $53 \%$ dos lotes/propriedades pesquisados, sua produção é predominantemente destinada ao autoconsumo do estabelecimento, pois também é empregado na alimentação animal. A cana está entre as principais culturas mencionadas pelos produtores, presente em 16 lotes/propriedades (40\% do total), ocupa área média de 0,5 hectare, sendo destinada exclusivamente à alimentação animal, porém o montante produzido se mostra insuficiente para suplementar a alimentação do rebanho bovino no período seco, na grande maioria dos casos. O feijão (cultivado por $38 \%$ do total de produtores), também, 
ocupa pequenas áreas (um hectare, no máximo) em quase todos os lotes/propriedades nos quais é observado; verificou-se uma expressiva diversidade dentre as espécies cultivadas (feijão guandu, feijão catador, feijão carioquinha, etc). Presente em $55 \%$ dos lotes/propriedades, a abóbora foi a segunda cultura mais citada e $40 \%$ dos produtores que a cultivam destinam a produção apenas para o autoconsumo. O quiabo, presente em $35 \%$ dos lotes/propriedades pesquisados, consiste em outra olerícola frequente entre os produtores, sua produção é quase que totalmente destinada à comercialização. Outras olerícolas que se destacam entre os produtores pesquisados são a pimenta, a alface e a cebolinha, mencionadas por $28 \%$ dos agricultores, e o maxixe, explorado por $25 \%$ dos produtores levantados. As pimentas são produzidas predominantemente para serem comercializadas, entre os 11 produtores que as produzem, apenas um utiliza esta olerícola somente para o autoconsumo. O cultivo da alface está quase sempre atrelado à produção de outras hortaliças, mas quatro lotes/propriedades praticamente se especializaram nesta olerícola: tratam-se de produtores cuja principal fonte de renda provém do cultivo de hortaliças e parte da produção é realizada em estufas/cobertura telada (cultivo protegido), a fim de atenuar os efeitos das altas temperaturas, taxas de insolação e também os efeitos das chuvas mais fortes, comuns na região, no verão. No caso do maxixe, a grande maioria dos produtores não faz semeadura e não possui área delimitada para o seu cultivo, explorando as plantas que nascem nas áreas, especialmente nas entrelinhas de outras culturas, contudo, a grande maioria dos agricultores explora o maxixe comercialmente. Tanto, no caso do maxixe, como da pimenta, os produtores justificavam o interesse por estas culturas em virtude da facilidade de comercialização, pois praticamente tudo que produzem conseguem vender rapidamente. A banana está presente em 10 lotes/propriedades (25\%), sendo a única fruta mencionada entre as principais culturas.

\section{Preparo do solo, tipo de mudas/sementes, irrigação e cultivos protegidos}

Em relação ao preparo do solo, 35 produtores (88\%) afirmaram que realizam tal operação por meio de tração mecânica, abrangendo cerca de metade das culturas (excluindo as áreas destinadas à pastagem). Áreas preparadas por meio de tração animal foram mencionadas por 11 produtores (28\%), totalizando neste caso, $32 \%$ das culturas exploradas. Quanto ao estabelecimento de técnicas de conservação do solo baseadas em plantio em nível e terraceamento, observou-se que em $38 \%$ dos lotes/propriedades pesquisados não são empregadas nenhuma destas técnicas. Plantios em nível foram citados por $63 \%$ dos produtores e com relação aos terraços, especificamente, estes estão presentes em $35 \%$ dos lotes/propriedades pesquisados; contudo, tais técnicas, na grande maioria dos casos, não abrangem toda a área onde se fazem necessárias.

O emprego de mudas/sementes certificadas foi verificado entre 23 produtores entrevistados $(57,5 \%)$, utilizadas, em média, no plantio/semeadura de duas culturas. As principais culturas cujo material de propagação é oriundo de empresas certificadas são o milho (10), a alface (6), o quiabo (5) e o almeirão (5). Em somente seis casos (15\%) foram observados produtores, cujas semeaduras/plantios das culturas presentes nos lotes/propriedades são majoritariamente realizadas com material certificado (quatro destes são agricultores especializados na produção de olerícolas folhosas). O percentual de

Cultura Agronômica, Ilha Solteira, v.24, n.1, p.103-118, 2015 
produtores que não empregam mudas/sementes certificadas é considerável (42,5\%), mas cabe destacar dois aspectos diferentes ligados a esta questão: a utilização de material de propagação produzida nos próprios lotes/propriedades ou oriundas de trocas/doações de outros produtores pode ser uma estratégia para reduzir a dependência de insumos externos, mas, em alguns casos, a utilização de mudas/sementes não certificadas ocorre por falta de recursos e o plantio de qualquer material pode aumentar os riscos e incertezas no que se referem aos processos produtivos.

Entre os produtores pesquisados, 14 (35\%) afirmaram que dispõem de sistemas de irrigação, com destaque para o gotejamento. Estes agricultores irrigam em média $40 \%$ das culturas exploradas, sendo que, entre estas, destacam-se as hortaliças folhosas. A região apresenta chuvas concentradas no verão e invernos marcados por estiagens, o que torna necessário, na grande maioria dos casos, complementar o fornecimento de água por meio da irrigação para atender às exigências hídricas das culturas, mas observa-se que quase dois terços dos agricultores não dispõem de sistemas de irrigação.

Com relação aos cultivos protegidos (estufas e/ou telados), foram observados 10 produtores (25\%) que produzem pelo menos uma cultura desta forma; sendo que, em média, $35 \%$ dos cultivos mencionados por estes agricultores são protegidos. Este tipo de infraestrutura e a irrigação permitem a manutenção da produção de algumas culturas durante todo o ano, mas como se pode constatar, somente uma minoria dos produtores dispõe desses meios.

\section{Análise, correção e adubação do solo}

No que se refere especificamente à realização de análises do solo por parte dos agricultores pesquisados, observou-se que apenas sete produtores (18\%) adotam, de forma periódica, tal prática; embora, em alguns casos, a periodicidade da realização da análise não seja adequada, como aqueles que realizam análise de solo em um intervalo superior a três anos. Dentre os 33 que não realizam periodicamente análises de solo, 18 afirmaram que a análise já foi realizada na área pelo menos uma vez desde a ocupação pelo respectivo agricultor; na grande maioria destes casos, a iniciativa partiu do órgão que presta assistência técnica ao lote/propriedade. Observações realizadas durante a pesquisa de campo indicam que a não realização de análises do solo não se deve unicamente ao preço pago para fazer a análise, mas também, à falta de recursos para posteriormente realizar a adubação/correção do solo indicada. De uma forma geral, os agricultores demonstraram estar cientes dos benefícios da adoção de tal prática, sendo que, apenas, cinco agricultores julgam-na como desnecessária.

No que tange à aplicação de calcário nos lotes/propriedades pesquisados, observou-se que 13 produtores (33\%) não realizam a aplicação do corretivo em suas áreas de cultivo. Quando questionados, muitos destes agricultores afirmaram que não realizam tal aplicação, em virtude de explorarem áreas cujos "solos são bons", o que dispensaria a calagem. Tal conclusão, na maioria dos casos, baseia-se no fato da produção obtida estar de acordo com as expectativas destes produtores. Dentre os demais, 27 produtores $(67,5 \%)$, a aplicação de calcário se dá nas áreas destinadas a $61 \%$ das culturas (em média). 
Com relação à adubação mineral, verificou-se que apenas cinco agricultores (14\%) não adotam tal prática. Ao analisar os fatores que influenciam a decisão do agricultor em realizar ou não a adubação mineral, observou-se que uma minoria dos produtores pesquisados $(20 \%)$, entre aqueles que realizam esta prática, toma a decisão com base em recomendações técnicas, mas a grande maioria opta por realizar este tipo de adubação com base em experiência e critérios próprios.

\section{Utilização de agrotóxicos}

A maioria dos produtores $(57,5 \%)$ não utiliza herbicidas em seus lotes/propriedades. Entre aqueles que utilizam herbicidas, $65 \%$ aplicam tais produtos no máximo em duas culturas; sendo que as mais citadas se referem ao feijão, à mandioca, ao quiabo e ao coco, todos citados por três produtores, cada.

Com relação à utilização de acaricida/inseticida, verificou-se que 34 produtores (85\%) empregam este tipo de produto em seus cultivos. Em média, estes agrotóxicos são aplicados em duas culturas, dentre as quais destacam-se: feijão (sete), milho (quatro), pinha (três), alface (três), couve (três) e quiabo (três). Cabe destacar que estes agricultores cultivam, em média, sete culturas, de modo que, em média, cinco culturas não recebem este tipo de produto.

Sete dos produtores entrevistados (18\%) declararam que realizam aplicações de fungicida em pelo menos uma das culturas exploradas, neste caso destacam-se as frutíferas, em especial, a cultura da laranja e da pinha.

O levantamento dos aspectos responsáveis pela escolha e aplicação dos agrotóxicos empregados nos sistemas de cultivo, por parte dos agricultores pesquisados, bem como, as fontes de informação utilizadas para obter conhecimentos sobre tais produtos, indicaram que $45 \%$ dos agricultores baseiam-se em critérios/experiência próprias e em informações fornecidas por outros produtores; $30 \%$ recorrem diretamente a lojas revendedoras sem uma orientação prévia e $25 \%$ dos agricultores mencionaram determinações baseadas em recomendações de técnicos que prestam assistência nos lotes/propriedades.

\section{Planejamento das atividades}

Em uma questão dirigida especificamente à investigação dos fatores considerados no planejamento das atividades nos lotes/propriedades (Tabela 2), verificou-se que os principais aspectos considerados estão relacionados com as condições climáticas. Em virtude do baixo número de produtores que detém meios para superar em parte as condições desfavoráveis impostas pelo clima (como as estufas e os sistemas de irrigação), as condições climáticas passam a consistir no principal limitante do calendário de cultivo dos agricultores. A maioria dos entrevistados afirmou que o planejamento das atividades está diretamente ligado ao clima, o que inclui as épocas de semeadura/plantio. Muitos agricultores aguardam o período chuvoso para finalmente iniciarem os cultivos, este aspecto consiste em uma das causas da sazonalidade da produção.

Questões referentes às condições de mercado (preços, exigências dos consumidores e demanda, entre outros) foram citadas por 14 agricultores (35\%) como fatores considerados 
no planejamento das atividades e que influenciam diretamente na determinação das culturas a serem exploradas, na quantidade a ser produzida e, em alguns casos, na época de colheita. Dois destes produtores afirmaram que planejam a produção para colher na entressafra, momento mais favorável à comercialização.

Doze agricultores (30\%) afirmaram que observam as épocas recomendadas para a semeadura/plantio das culturas exploradas durante a realização do planejamento.

Tabela 2. Fatores considerados no planejamento das atividades nos lotes/propriedades, descritos pelos agricultores pesquisados.

\begin{tabular}{l|c|c}
\multicolumn{1}{c|}{ ASPECTOS MENCIONADOS } & $\mathbf{N}^{\mathbf{0}}$ PRODUTORES & $\boldsymbol{\%}$ \\
\hline Condições climáticas & 20 & 50 \\
\hline Condições de mercado (preços, exigências e demanda) & 14 & 35 \\
\hline Época de plantio das culturas a serem exploradas & 12 & 30 \\
\hline Fatores relacionados aos locais de cultivo, no & 11 & 28 \\
\hline Conhecimentos acerca das culturas & 5 & 13 \\
\hline Necessidades de consumo da família & 4 & 10 \\
\hline Disponibilidade de insumos & 2 & 5 \\
\hline Condição financeira & 2 & 5 \\
\hline Outros aspectos & 5 & 13 \\
\hline Fon Dasa
\end{tabular}

Fonte: Dados da Pesquisa, 2009.

Aspectos relacionados à distribuição das culturas na área foram mencionados por 11 agricultores (28\%), seis destes destacaram que durante o planejamento das atividades buscam dispor as culturas nos lotes/propriedades de modo a facilitar o manejo destas, principalmente, as condições de colheita e irrigação; enquanto os demais citaram condições relacionadas ao solo e à declividade da área (para evitar erosão do solo).

Outros dois fatores, embora menos citados, mostram a prevalência de algumas características dos agricultores familiares que são passadas de geração em geração: a escolha das culturas com base na experiência que possuem a respeito da mesma e o atendimento às necessidades de consumo da família. Costabeber e Caporal (2003) enfatizam a relevância da produção destinada ao autoconsumo por parte dos agricultores familiares, como estratégia de importância no que e refere ao alcance da segurança alimentar das comunidades rurais; ainda segundo os autores, tal aspecto ressalta a ampla capacidade da agricultura familiar em contribuir de forma decisiva para a superação dos problemas relacionados à fome.

Quanto à organização dos produtores para a aquisição de insumos, foram verificados apenas quatro casos em que os agricultores compram ou já compraram insumos de forma conjunta. Neste grupo, estão presentes três agricultores que o fazem por meio de associações, um agricultor cooperado e outro que realiza tais aquisições por meio de um grupo informal (um deles utilizou dois tipos de organização).

De maneira geral, os produtores declararam que as formas de cultivo dos produtos destinados ao autoconsumo não eram diferentes daquelas dos produtos destinados à comercialização, embora na questão específica sobre utilização de insumos verificou-se que

Cultura Agronômica, Ilha Solteira, v.24, n.1, p.103-118, 2015 
um pequeno percentual de agricultores adubava em função da perspectiva de retorno econômico.

Ainda em relação ao planejamento das atividades, a maioria dos entrevistados (22 agricultores - 55\%), em uma questão específica, afirmou que verifica as condições de comercialização da produção antes de optar pela exploração de determinada cultura ou mesmo iniciar uma nova atividade; já os demais, que também somam um percentual significativo (45\%), afirmaram que iniciam os cultivos para posteriormente verificar as possibilidades de comercialização. A falta de informações consistentes e a insuficiência de compreensão dos mercados de destino aumentam a possibilidade de insucesso no processo de comercialização. Em virtude de tais aspectos, muitos agricultores conseguem obter produtos em quantidades elevadas, sem, contudo, dispor de meios eficientes para a venda do montante produzido. Guanziroli (2007) chama a atenção para a necessidade de se observar a tendência do mercado, a fim de se produzir aquilo que realmente possua demanda e perspectivas de integração agroindustrial (ou então, outra forma de inserção no mercado), para, posteriormente, analisar as questões ligadas às tecnologias a serem empregadas na produção e finalmente o crédito que porventura se faça necessário; este comportamento seria favorecido pela garantia do máximo de apropriação de renda e de valor pelos agricultores familiares, no entanto, para que isso venha a ocorrer, é preciso compreender a dinâmica dos mercados.

\section{Dificuldades relativas à produção vegetal}

Ao se levantar junto aos agricultores possíveis entraves ligados à produção vegetal, observou-se que nenhum aspecto específico predominou (Tabela 3). As principais dificuldades citadas estão relacionadas às adversidades climáticas, particularmente ao período seco que na região se estende por seis meses (em média); e a falta de infraestrutura necessária para a superação das limitações climáticas.

Tabela 3. Dificuldades relacionadas com a produção vegetal, citadas pelos agricultores pesquisados.

\begin{tabular}{l|c|c}
\hline \multicolumn{1}{c|}{ DIFICULDADES MENCIONADAS } & $\mathbf{N}^{\mathbf{0}}$ PRODUTORES & $\boldsymbol{\%}$ \\
\hline Irrigação & 7 & 18 \\
\hline Dificuldade financeira & 7 & 18 \\
\hline Fatores relativos à mão de obra & 7 & 18 \\
\hline Fatores relacionados à comercialização & 7 & 15 \\
\hline Estiagem/chuvas excessivas & 6 & 15 \\
\hline Falta de água no lote/propriedade & 6 & 15 \\
\hline Pragas & 6 & 13 \\
\hline Falta de implementos agrícolas & 5 & 10 \\
\hline Assistência técnica & 4 & 8 \\
\hline Não encontram dificuldades & 3 & 8 \\
\hline Outras dificuldades & 3 & \\
\hline
\end{tabular}

Fonte: Dados da Pesquisa, 2009.

Entre os agricultores entrevistados, $18 \%$ afirmaram que a maior dificuldade consiste na falta de sistemas de irrigação. $O$ baixo percentual de produtores que dispõem de 
tecnologias necessárias para manutenção dos índices de produtividade, ou mesmo da produção, independentemente dos níveis de precipitação, explica o relevante percentual de produtores que vendem esporadicamente seus produtos.

Outro fator que também se entrelaça com os anteriores é a falta de recursos financeiros, citada por $18 \%$ dos entrevistados, devido à dificuldade de obter crédito ou pela opção de não querer contrair dívidas.

Também 18\% mencionaram dificuldades relacionadas, especificamente, à mão de obra. Com relação a este fator, é válido ressaltar que em $60 \%$ dos lotes/propriedades pesquisados, os trabalhos são desenvolvidos exclusivamente pela família, sem contratação de mão de obra de terceiros, como a maioria dos agricultores apresenta idade relativamente avançada para o tipo de trabalho desenvolvido, a força de trabalho passa a consistir em um fator limitante, sobretudo, no caso das famílias em que as atividades agrícolas são majoritariamente desempenhadas pelo casal.

De forma circular, pois parte dos agricultores entrevistados inicialmente ao serem questionados sobre dificuldades ligadas à comercialização se referiam a fatores relativos à produção, $18 \%$ dos produtores identificaram que as dificuldades estavam relacionadas com o processo de comercialização.

A escassez e/ou falta de água foram apontadas por 15\% dos agricultores como aspecto limitante para a produção vegetal, pois várias propriedades não possuem poços semiartesianos. Na primeira fase da pesquisa (2008) verificou-se que para $62 \%$ das famílias, os poços semi-artesianos consistiam nas principais fontes de água para o consumo familiar, sendo que $16 \%$ destes eram de uso comunitário. Tanto no caso dos produtores que utilizavam poços semi-artesianos comunitários, como os $18 \%$ que possuíam poços cacimba, a utilização da água oriunda de tais poços na produção nem sempre é inviável, pois a quantidade, em muitos casos, se mostra insuficiente.

Dificuldades relacionadas ao controle de pragas foram citadas por $15 \%$ dos produtores, entre os 40 entrevistados. Um aspecto constatado, que pode contribuir para a compreensão de tal dificuldade, está ligado aos fatores que determinam a escolha e a aplicação dos agrotóxicos nos sistemas de cultivo. Conforme, já mencionado, vários produtores entrevistados na segunda fase da pesquisa afirmaram que a escolha dos produtos fitossanitários empregados na produção era baseada na experiência própria $(25 \%)$ e em conselhos de outros produtores (20\%). O distanciamento dos órgãos de assistência técnica e/ou a baixa qualidade da assistência recebida dificulta o acesso a uma formação técnica por parte dos produtores, distorcendo o processo de tomada de decisão em vários âmbitos do processo produtivo, com destaque para os aspectos que envolvem o controle fitossanitário.

Embora várias questões levantadas apontem entraves estreitamente relacionados ao acesso às informações/aconselhamentos técnicos, o percentual de agricultores que consideraram a assistência técnica como um problema que dificultava o incremento da produção vegetal foi de apenas $10 \%$. Os agricultores do Reassentamento Nossa Senhora de Fátima (Pereira Barreto), atualmente, não recebem assistência técnica de nenhum órgão em específico. De modo semelhante, os agricultores do Projeto Cinturão Verde (Ilha Solteira), Cultura Agronômica, Ilha Solteira, v.24, n.1, p.103-118, 2015 
quando necessitam de informações técnicas fornecidas por órgãos públicos recorrem à CATI (Coordenadoria de Assistência Técnica Integral), por meio da Casa da Agricultura local. Os assentamentos Timboré (Andradina), Rio Paraná (Castilho) e Assentamento São Joaquim (Castilho) recebiam assistência técnica do INCRA (Instituto Nacional de Colonização e Reforma Agrária) e do ITESP (Fundação Instituto de Terras do Estado de São Paulo); já no caso dos assentamentos Terra é Vida (Pereira Barreto) e Estrela da Ilha (Ilha Solteira), o órgão responsável pela assistência técnica era somente o INCRA. Entre os agricultores assentados (27), os quais recebem assistência técnica de órgãos governamentais que mantém profissionais fixos nos assentamentos, apenas quatro a classificaram como "ótima" (1) ou "boa" (3) a qualidade da assistência técnica recebida, na época da pesquisa (2009).

A falta de implementos foi citada por $13 \%$ dos entrevistados. Com relação a este último item, em sua maioria, os produtores se referem à falta ou dificuldade de acesso a tratores. Entre os entrevistados, uma minoria declarou possuir trator, sendo alguns já bastante antigos e com baixa potência, o que leva os produtores a depender de máquinas alugadas das associações de produtores, prefeituras ou de particulares.

\section{Produção vegetal: investimentos necessários}

De forma complementar, questionou-se junto aos produtores quais seriam os investimentos considerados necessários para proporcionar aumentos na produção e/ou na produtividade das culturas exploradas. Observa-se na Tabela 4, que investimentos em infraestrutura voltados para a superação de limitações decorrentes de condições climáticas desfavoráveis (irrigação e cultivo protegido) consistiram nos principais itens mencionados pelos agricultores.

Tabela 4. Investimentos considerados como necessários pelos agricultores pesquisados para proporcionar aumentos na produção e/ou na produtividade das culturas exploradas.

\begin{tabular}{l|c|c}
\hline \multicolumn{1}{c|}{ FATORES MENCIONADOS } & $\mathbf{N}^{\mathbf{0}}$ PRODUTORES & $\mathbf{\%}$ \\
\hline Irrigação & 19 & 48 \\
\hline Cultivo Protegido & 7 & 18 \\
\hline "Outras culturas" & 5 & 13 \\
\hline Adubação/calagem & 4 & 10 \\
\hline Implementos & 3 & 8 \\
\hline Mão de obra & 3 & 8 \\
\hline Melhorar condição do solo & 2 & 5 \\
\hline Aumentar a área explorada & 2 & 5 \\
\hline Poço & 2 & 5 \\
\hline Controle de Pragas & 2 & 5 \\
\hline Reforma de pasto & 2 & 5 \\
\hline Outros & 1 & 4 \\
\hline \multicolumn{2}{c}{ Fonte: Dados da Pesquisa, 2009. } &
\end{tabular}

Quase metade dos agricultores entrevistados (19) julga como necessários investimentos direcionados à implantação e/ou à ampliação de sistemas de irrigação nos lotes/propriedades explorados, como forma de manter a regularidade da produção durante 
todo o ano.

Ao responder a questão que visava levantar os investimentos considerados como necessários para proporcionar aumentos na produção e/ou na produtividade das culturas exploradas, cinco agricultores (10\%) não se prenderam a incrementos nos sistemas de cultivo até então explorados, afirmando que pretendiam investir em novas culturas. $\mathrm{O}$ principal aspecto considerado, neste caso, está ligado com a possibilidade de se cultivar produtos que tenham maior aceitação no mercado.

Investimentos em adubação e em calagem foram mencionados por quatro produtores (10\%). O detalhamento dos sistemas de cultivo realizado na segunda fase da pesquisa demonstrou que 13 produtores (33\%) não realizavam a aplicação do corretivo em suas áreas de cultivo e apenas cinco agricultores (14\%) não realizam adubação mineral.

Ao se analisar as dificuldades mencionadas pelos agricultores, bem como os investimentos considerados como necessários para proporcionar aumentos na produção e/ou na produtividade das culturas exploradas, observa-se que ambos os aspectos convergem para os obstáculos impostos pelas condições climáticas e pela falta de infraestrutura necessária para a superação de tais empecilhos. Em estudo realizado por Sant'Ana \& Tarsitano (2009), na Microrregião de Andradina/SP, constatou-se que grande parte das famílias pesquisadas não dispõe de recursos, infraestrutura e/ou capacitação técnica que possibilitem intensificar os processos produtivos, entretanto, os referidos autores destacam que parte das famílias não tem como projeto prioritário seguir o caminho da intensificação. Destaca-se que, mesmo diante de dificuldades, as quais representam entraves no potencial de geração de renda dos estabelecimentos explorados, a grande maioria das famílias não considera tais obstáculos como fatores que desestimulariam a sua permanência no lote/propriedade explorado.

\section{CONSIDERAÇÕES FINAIS}

Por meio das informações referentes ao planejamento das atividades relacionadas aos sistemas de cultivos explorados pelos agricultores, verifica-se que as condições climáticas consistem no principal fator considerado durante a realização do planejamento. O relativo baixo percentual de produtores que dispõe de tecnologias necessárias para manutenção da produção e da produtividade sem depender dos níveis de precipitação pluviométrica, ou mesmo de tecnologias que atenuem os efeitos dos estresses provocados pelas condições climáticas em geral, consiste no principal motivo observado para o alto percentual de produtores que vendem esporadicamente ou de forma descontínua os seus produtos ao longo do ano. Assim, a precariedade da infraestrutura, encontrada na grande maioria dos lotes/propriedades pesquisados, cujas características contribuem para a obtenção de uma produção marcada pela sazonalidade, consiste em uma das principais dificuldades encontradas pelos agricultores familiares no que diz respeito aos sistemas de cultivo investigados. Tal aspecto ressalta a importância da exploração de culturas que apresentem relativa rusticidade e se mostrem menos sensíveis às condições climáticas da região. 
A adoção de práticas que não requerem investimentos elevados, nem tecnologias que se mostrem muito sofisticadas, como a correção da acidez do solo com base em análises químicas, pode resultar em avanços no que se referem aos índices de produtividade das culturas exploradas pelos agricultores em questão.

$\mathrm{O}$ detalhamento dos sistemas de cultivo permitiu constatar que aliadas à precariedade da infraestrutura dos lotes/propriedades pesquisados, as deficiências referentes à assistência técnica e extensão rural, consistem também em aspectos limitantes para o desenvolvimento dos sistemas de cultivo, com reflexos negativos no processo de comercialização e, consequentemente, no potencial das famílias em gerar renda nos lotes/propriedades explorados. Os aspectos levantados indicam a necessidade de políticas públicas que facilitem os investimentos em infraestrutura produtiva, associadas a programas de assistência técnica e extensão rural focados nas especificidades locais que sejam efetivos em termos de superação dos entraves constatados.

\section{AGRADECIMENTOS}

À FAPESP (Fundação de Amparo à Pesquisa de São Paulo) pela concessão de bolsa de Iniciação Científica à primeira autora e ao CNPq pelo auxílio pesquisa concedido ao segundo autor.

\section{REFERÊNCIAS BIBLIOGRÁFICAS}

BUAINAIN, A. M.; ROMEIRO, A.R.; GUANZIROLI, C. Agricultura Familiar e o Novo Mundo Rural. Sociologias, Porto Alegre, ano 5, n. 10, p.312-347, 2003. Disponível em: <http://www.scielo.br/scielo.php>. Acesso em: 10 mar. 2009.

CATI - COORDENADORIA DE ASSISTÊNCIA TÉCNICA INTEGRAL. Mapa da Agricultura Paulista. Projeto LUPA - Levantamento Censitário das Unidades de Produção Agropecuária do Estado de São Paulo, 2007/08. Disponível em: <http://www.cati.sp.gov.br/Cati/_servicos/lupa/lupa.shtml>. Acesso em: 10 out. 2009.

COSTABEBER, J. A.; CAPORAL, F. R. Possibilidades e alternativas do desenvolvimento rural sustentável. In: VELA, H. (Org.). Agricultura Familiar e Desenvolvimento Rural Sustentável no Mercosul. Santa Maria: Editora da UFSM/Pallotti, 2003. p. 157-194.

FAVERO, E.; DIESEL, V.; HELDWEIN, A. A seca enquanto limitante da reprodução dos agricultores familiares no Sul do Brasil. In: CONGRESSO BRASILEIRO DE SISTEMAS DE PRODUÇÃO-SBSP, 7, Fortaleza, 2007. Agricultura Familiar, Políticas Públicas e Inclusão Social, 2007. v. único. p. 1-15. 
GUANZIROLI, C. E. PRONAF dez anos depois: resultados e perspectivas para o desenvolvimento rural. Revista de Economia e Sociologia Rural, Brasília, v. 45, n. 2, p.301-328, 2007.

INSTITUTO BRASILEIRO DE GEOGRAFIA E ESTATÍSTICA - IBGE. Censo Agropecuário. Rio de Janeiro: IBGE, 2006. Disponível em: < http://www.ibge.gov.br/>. Acesso em: 10 jan. 2011.

INSTITUTO BRASILEIRO DE COLONIZAÇÃO E REFORMA AGRÁRIA - INCRA. Prestação de contas anual: Relatório de gestão do exercício de 2009. São Paulo: Superintendência Regional de São Paulo, 2010. 189 p.

SANT'ANA, A. L.; TARSITANO, M. A. A. Tipificação das famílias de oito assentamentos rurais da região de Andradina (SP), com base em diferentes estratégias de produção e comercialização. Revista de Economia e Sociologia Rural, Piracicaba, v. 47, n. 3, p.615636, 2009.

SOUZA, P. M.; FERREIRA, V. R.; PONCIANO, N. J.; BRITO, M. N. Otimização econômica, sob condições de risco, para agricultores familiares das regiões Norte e Noroeste do Estado do Rio de Janeiro. Pesquisa Operacional, Rio de Janeiro, v. 28, n. 1, p.123-139, 2008. Disponível em: 〈http://www.scielo.br/scielo〉. Acesso em: 26 mar. 2011. 